\title{
Large-scale determinants of trematode infections in intertidal gastropods
}

\author{
Robert Poulin*, Kim N. Mouritsen \\ Department of Zoology, University of Otago, PO Box 56, Dunedin, New Zealand
}

\begin{abstract}
The influence of latitude, substrate type, tidal level, and host shell size on trematode species-richness and prevalence were assessed using published data on 255 samples from 54 species of marine intertidal gastropods. The analyses were performed at different levels of statistical independence: among all samples, across snail species, and using phylogenetically independent contrasts. Repeatability analysis showed that both trematode species richness and prevalence could be considered as snail species traits. Although there was much within-species variation among values obtained from different samples, the among-species variation was much higher. After removing the confounding effect of sample size, positive relationships between trematode prevalence and species richness were observed at all levels of analysis, highlighting the additive nature of trematode infections in snails. The latitude at which samples were collected had a significant effect on trematode species richness across all samples, but this influence disappeared at higher levels of analyses. There was no evidence that host shell size (as well as life-span and population density) was associated with either trematode species richness or prevalence. Tidal level and substrate type (rocky versus softsediment) where samples were collected had significant effects on trematode species richness across all samples. These effects could not be verified at higher levels of analyses. Overall, the results point toward an important role of local, small-scale factors in determining the number of trematode species infecting snails and the proportion of infected snails in a population.
\end{abstract}

KEY WORDS: Comparative analysis · Latitudinal gradients · M olluscs · Prevalence - Sampling effort · Species richness

\section{INTRODUCTION}

The search for general laws in ecology is increasingly, and sometimes with great success, adopting a macroecological approach (Brown 1995, Lawton 1999). For instance, large-scale spatial patterns in the diversity of parasitic organisms, or in the prevalence and intensity of parasitic infections among hosts, have recently provided new insights into wildlife epidemiology and the evolutionary biology of diseases (Poulin et al. 2000, Hudson et al. 2002). The types of parasites infecting hosts and the severity of infection vary among individual hosts, among host populations or geographical areas, and among host species. Robust patterns are emerging from several recent macroecological studies: several ecological or life-history traits of hosts are proving reliable predictors of infection parameters across host species (see reviews by Poulin 1997, Morand 2000). These studies have focused mainly on vertebrates and terrestrial systems; however, there is no comparable evidence from marine invertebrate hosts, although they harbour a rich fauna of parasites (Rohde 1993).

Intertidal gastropods and their trematode parasites are good candidates for macroecological studies of infection patterns, for at least 3 reasons. First, relatively more information is available on these host-parasite systems than on other systems involving invertebrate hosts. Second, trematodes are the main, and in many cases the only, metazoan parasites of gastropods. They use snails as their first intermediate hosts, in which their larval stages (rediae or sporocysts) go through 
phases of asexual reproduction. Cercariae produced asexually usually leave the snail to encyst in a second intermediate host, and complete their life cycle when this host is ingested by a suitable definitive host, i.e. fish or more commonly shorebirds. The association between trematodes and gastropods is an ancient one (Kearn 1998); in contrast, very few other metazoans have colonised snail hosts over evolutionary time. Third, trematodes cause major fitness reductions in their snail hosts. Often, trematode-infected snails incur much higher mortality than their uninfected conspecifics under natural conditions (Lauckner 1987, J ensen \& M ouritsen 1992, Huxham et al . 1993). In addition, infection by trematodes normally results in reduced reproductive output in snails, and very often in complete castration of the host (Sousa 1983, Pearson \& Cheng 1985, Huxham et al. 1993, Lafferty 1993a; see review in M ouritsen \& Poulin 2002). The strong selective pressures placed on snail hosts by trematodes have resulted in adaptive changes in snail life-history traits in heavily parasitised populations (Ruiz 1991, Lafferty 1993b, Krist 2001). The macroecological determinants of trematode infections can, therefore, be important drivers of snail population dynamics and evolution.

Several predictions can be made regarding the effect of ecological variables on trematode infections of snails. First, we might expect the relative number of trematode species infecting snails to increase with decreasing latitude. Latitudinal gradients in species diversity are among the best-documented large-scale patterns in ecology (Rosenzweig 1995, Gaston \& Blackburn 2000). Among parasitic organisms, there is good evidence that the species richness of assemblages of ectoparasites on marine fish increases with decreasing latitude, or increasing water temperature (Rohde 1993, 1999, Poulin \& Rohde 1997, Rohde \& Heap 1998). The many processes thought to be responsible for these gradients (see Gaston \& Blackburn 2000 for review) can also act on trematodes directly, or indirectly by influencing the diversity of the intermediate and definitive hosts in their life cycles. For instance, the diversity of macroinvertebrates in soft-sediment intertidal areas increases toward the tropics (Attrill et al. 2001), although their biomass peaks in temperate regions (Ricciardi \& Bourget 1999). Second, we predict that trematode infections should be more common in softsediment microhabitats than on rocky substrates within the intertidal zone. More shorebirds, both in terms of individuals and species, visit soft-sediment flats than rocky shores (e.g. Nybakken 1993), and on both types of substrate birds are more likely to feed in the upper than in the lower part of the intertidal range because of longer exposure times. Although many intertidal trematode species mature in fish, shorebirds are the definitive hosts of the vast majority of trema- todes found in intertidal snails, with eggs from adult worms expelled in bird faeces. Even on a small scale, proximity to birds increases the likelihood of snails becoming infected by trematodes (e.g. Smith 2001), and thus the habitat of snails relative to birds can be an important determinant of trematode infection levels. Third, we might expect that some of the ecological and life-history variables that affect levels of parasitism in vertebrate hosts will also influence trematode infections in snails. Some of these variables, such as host body size, host longevity or host population density, are consistently correlated with the number of parasite species exploiting vertebrate host species (see Poulin 1997, M orand \& Poulin 1998, M orand 2000). Larger hosts provide more space and nutrients for parasites and ingest more food (and thus parasite-infective stages), long-lived hosts represent more permanent habitats for parasites, and high host densities facilitate parasite transmission by providing more targets per unit area; surely these factors are important for hostparasite associations other than those involving vertebrate hosts.

In this study, we test the above 3 predictions using data on trematode species richness and prevalence among samples of marine intertidal gastropods. Several studies have reported considerable variation in the number of trematode species infecting snails, and in their prevalence, between samples of the same snail species taken no more than a few $\mathrm{km}$ apart (e.g. Pohley 1976, Huxham et al. 1993, Lafferty 1993b, Curtis 1997). If trematode infections are variable within snail species on a modest geographical scale, they may be features of local snail populations and not of snail species. Thus different samples of the same snail species may represent more or less independent observations. However, if variation within snail species is lower than variation among species, infection parameters may be traits of snail species, even if variable (see Arneberg et al. 1997). At a higher level, when comparing ecological variables such as infection parameters among species, it is not always clear whether phylogenetic influences should be taken into account (Westoby et al. 1995a,b). Because closely related species share many traits, it can influence their susceptibility to infection; however, controlling for phylogenetic influences can only help to eliminate the effects of confounding variables (Harvey 1996). Therefore, in this study we analyse the influences of ecological variables on infection of snails by trematodes at different scales, which provide increasing levels of statistical independence among data points. At one extreme, an analysis across all samples can reveal existing patterns in trematode infections in snails; at the other extreme, an analysis based on phylogenetically independent contrasts can shed some light on the processes underlying the patterns. 


\section{MATERIALS AND METHODS}

Data collection. Data were gathered from published studies on trematode infections of snails. First, we surveyed the literature cited in the reviews by Kuris \& Lafferty (1994) and Pechenik et al. (2001). Second, we performed a search in our own reprint collections, in electronic databases (Zoological Record and Aquatic Sciences and Fisheries Abstracts), and among the references cited in key papers. We included only studies on intertidal or shallow subtidal gastropods parasitised by the first larval stages (rediae or sporocysts) of trematodes. In addition, we included only data from studies in which snails were examined for trematodes by dissection. Samples from which no trematodes were found were excluded, as they may represent false negatives. It is possible that some zero-prevalence samples are indeed indicative of an absence of trematodes in a particular snail population; however, since most such data go unpublished, and those few that are published are usually based on small numbers of snails examined, we found it preferable to exclude them. Some studies reported data on several samples of snails from the same species but different locations within the same area, and treated those samples as independent; other studies reported only pooled data from several samples. We accepted the reasons given by the authors of the original studies for treating samples independently or together, and compiled data from individual or pooled samples accordingly. Most samples were collected during the summer months, a few over the entire year; a preliminary analysis showed no effect of the timing of sampling on our dependent variables, and we thus treated all samples together independently of season.

The 2 dependent variables in our analyses were trematode species richness and trematode prevalence. Species richness is the total number of trematode species occurring as rediae or sporocysts in a sample of snails. Prevalence is the percentage of snails infected by any of these trematodes in the sample. Hence, it is not merely the sum of the respective prevalences of the different trematode species in a sample, in which some snail individuals may harbour more than 1 species of trematodes.

The number of hosts examined can have an important influence on estimates of parasite species richness (Walther et al. 1995) and, to a lesser extent, prevalence (Gregory \& Blackburn 1991). Therefore, we excluded samples in which fewer than 75 snail hosts had been examined for trematodes. In addition, we recorded sample size for each snail sample and controlled for this potentially confounding variable in the analyses.

We recorded 6 ecological or life history variables that may be determinants of trematode infection in snails: (1) the latitude at which the sample was collected, with no difference made between north and south latitudes; (2) the substrate type, either rocky (cliff face, boulders or stony beach) or soft (mud or sand), on which the snails were found; (3) the tidal level at which they were collected, either around/just below the low water mark or above the mid-intertidal; (4) the maximum shell length or width of the snails collected; (5) the normal life-span of the snails; and (6) the density of snails (no. $\mathrm{m}^{-2}$ ) at the site of collection. Data on all 6 variables were not available for most samples, and the analyses are therefore based on different numbers of observations, depending on which variables are included.

Data on species richness, prevalence, and sample size were $\log _{10}$-transformed, after which they showed either a normal or approximately normal distribution. Data on latitude were slightly right-skewed and their distribution could not be normalised by any transformation, so they were left untransformed. Substrate type and tidal level were coded as binary variables. In analyses requiring mean values for each snail species, averages were obtained (using log-transformed data where appropriate) across all samples from the same snail species, with weighting for sample size. N ote that data on shell size, life-span and substrate type varied little or not at all among samples from the same snail species.

Analyses. Analyses were performed at 4 different levels: across all samples, across samples within snail species, across species values, and across phylogenetically independent contrasts. These represent increasing levels of statistical independence between data points. For the first 3 levels, data were analysed using standard parametric tests following the log-transformation of some variables (see above). Across all samples, we tested for effects of latitude, tidal level and substrate type, as well as sample size as a confounding variable, using multiple regressions; trematode species richness and prevalence were the dependent variables. A cross samples from the same species, only latitude and sample size could be entered as predictor variables, since tidal level data were not sufficient and substrate type did not vary among samples from the same snail species. Only snail species represented by 7 or more samples were included in these analyses.

Across species values, the same multiple-regression approach was applied using sample size, latitude and substrate type as predictor variables; tidal level was not included because it characterises a sample and is not necessarily a species trait. In addition, we included latitudinal range as a predictor variable. This was treated as a binary variable: snail species were classified either as represented only by samples from the same latitude (i.e. range in latitude $=$ difference 
between maximum and minimum latitudes $=0^{\circ}$ ), or by samples from a range of latitudes; latitudinal range corresponds to a large extent with the number of samples available per species. The effects of shell size, lifespan and density were evaluated separately, because data on these variables were only available for a few species and their inclusion in a multiple regression would have substantially limited the power of the analysis.

To determine whether trematode species richness and prevalence are true species characters, i.e. features that vary less among samples from the same species than among snail species, we performed a repeatability analysis following that of Arneberg et al. (1997). Using snail species for which at least 2 samples were available, we analysed the variation in trematode species richness and prevalence using an ANOVA in which snail species was the only factor. A significant effect of snail species would indicate that the measures are repeatable within species, i.e. that they are more similar to each other than to measures from other snail species. We estimated the proportion of the variance that exists among species, rather than within species, by using the coefficient of intraclass correlation, $r_{1}$ (Sokal \& Rohlf 1995, p. 214).

If trematode species richness and prevalence are traits of snail species, we might expect values for closely related species to be more similar to one another because of shared recent ancestry. To account for the potential influence of phylogeny on the nonindependence of species values, we used the phylogenetically independent contrasts method (Felsenstein 1985, Harvey \& Pagel 1991). The phylogeny of gastropods is still not fully resolved. Here, we constructed a working phylogeny using proposed relationships among families and higher taxa from Kantor (1996), Ponder \& Lindberg (1997), Beesley et al. (1998), and Winnepenninckx et al. (1998), and relationships within families from other sources (Houbrick 1984, Reid 1990, Hickman 1996, Reid et al. 1996). Independent contrasts were computed between sister taxa in the gastropod phylogeny, using the program Comparative Analysis by Independent Contrasts (CAIC), version 2.0 (Purvis \& Rambaut 1994). Contrasts in continuous variables (sample size, trematode species richness, trematode prevalence, latitude and shell size) were derived from log-transformed data; substrate type was also included as a dichotomous variable. We did not control for the dichotomous variable latitudinal range (or the number of samples per snail species), because too many contrasts in this variable equalled zero, and average sample size was a better correlate of trematode species richness. Regression and correlation analyses were forced through the origin (see Garland et al. 1992).

\section{RESULTS}

In total, we obtained data from 255 snail samples, representing 54 gastropod species and 18 families. The data are derived from the examination of over 355000 individual snails, with a median sample size of 350 snails (range 75 to 32307 ), and were obtained from 79 different studies published between 1935 and 2001. The whole data set (including sources) is available as an electronic supplement (Excel format) on the journal's website (www.int-res.com/journals/suppl/poulinappendix.xIs), or from either author upon request.

\section{Analyses across samples}

The frequency distribution of both trematode species richness and prevalence values were skewed toward the left (Fig. 1); approximately $50 \%$ of snail samples contained 3 or fewer trematode species, and the total prevalence of trematode infections was less than 10 to $15 \%$ in more than half of the samples. Trematode species richness correlated positively with sample size $(r=$ $0.486, \mathrm{~N}=234, \mathrm{p}=0.0001$ ) as did, but only weakly,
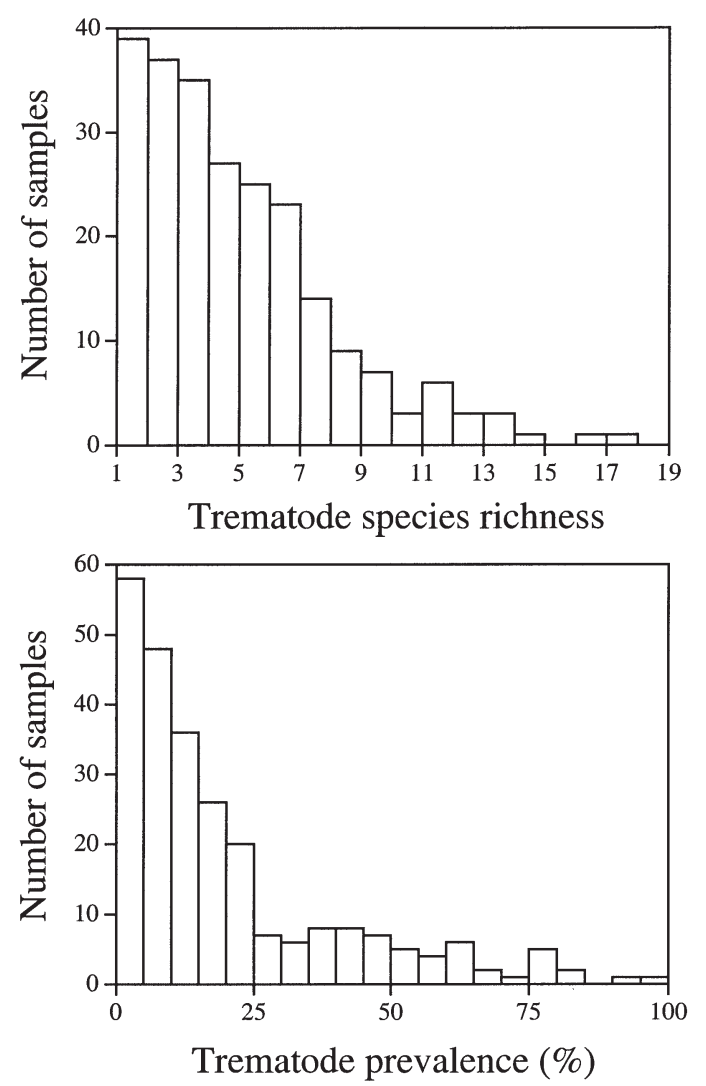

Fig. 1. Frequency distribution of trematode species richness and prevalence values among samples (234 samples for species richness, 251 for prevalence) of snail hosts 
prevalence $(r=0.137, N=244, p=0.0329)$. Trematode prevalence and species richness correlated positively and relatively strongly across all samples ( $r=0.559$, $\mathrm{N}=233, \mathrm{p}=0.0001$ ); the scatter of points show a triangular pattern suggesting that snail populations harbouring a single trematode species can show a range of prevalences, whereas those harbouring several species are invariably infected at high prevalence (Fig. 2). The positive relationship between richness and prevalence remains strong $(r=0.556, N=230, p=0.0001)$ after controlling both variables for the effect of sample size, using a partial correlation.

The effects of latitude, tidal level and substrate type on trematode richness were evaluated across samples using a multiple regression in which sample size was included as a confounding variable. The overall model explained $53 \%$ of the variance, with sample size as the main predictor of trematode richness (Table 1). We found that the effect of latitude was significant and positive: trematode species richness tended to increase with increasing latitude (Fig. 3). Substrate type and tidal level showed marginal effects on trematode richness (Table 1). Adding trematode prevalence, which covaries with species richness, to the model did not alter the outcome of the analysis. Similarly, the effect of these same predictor variables on trematode prevalence was assessed in a multiple regression, in which species richness was also included as a possible confounding variable. The overall model explained $37 \%$ of the variation in prevalence among samples (Table 1). We found no significant effect of latitude (Fig. 3), sample size or habitat type on trematode prevalence. Only trematode species richness and tidal level influenced prevalence values (Table 1).

The marginal effects of tidal level and substrate type on trematode species richness are more apparent when a larger portion of the data set is included, which

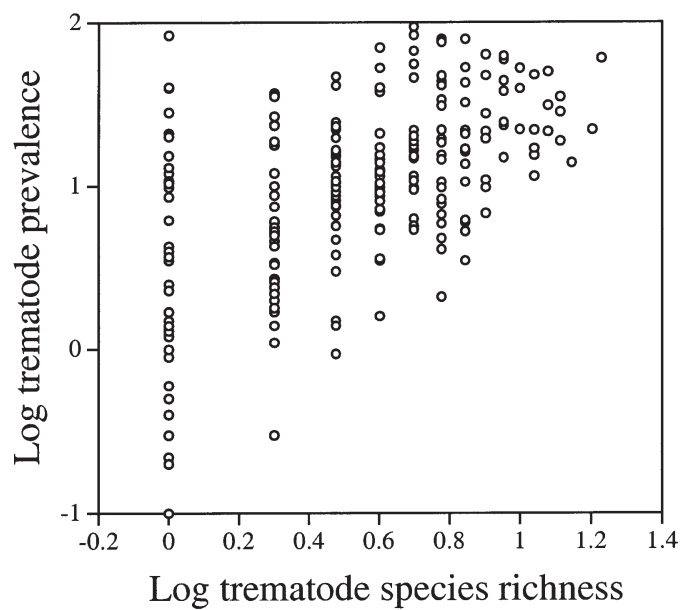

Fig. 2. Relationship between trematode prevalence and species richness across 230 samples of snail hosts
Table 1. Summary results of the multiple regression analyses of the determinants of trematode species richness and prevalence across snail samples or species

\begin{tabular}{|c|c|c|c|c|}
\hline \multirow[t]{2}{*}{ Predictors } & \multirow[t]{2}{*}{ F-ratio } & \multicolumn{3}{|c|}{ Partial regression } \\
\hline & & $t$ & $r^{2}$ & $\mathrm{p}$ \\
\hline \multicolumn{5}{|c|}{ Across samples: species richness } \\
\hline Sample size & & 6.72 & 0.42 & 0.0001 \\
\hline Latitude & & 4.03 & 0.20 & 0.0001 \\
\hline Substrate type & & 1.97 & 0.06 & 0.053 \\
\hline Tidal level & & 1.71 & 0.04 & 0.092 \\
\hline Total regression & $F_{4,63}=17.96$ & & 0.53 & 0.0001 \\
\hline \multicolumn{5}{|c|}{ Across samples: prevalence } \\
\hline Sample size & & 0.07 & 0.00 & 0.949 \\
\hline Species richness & & 3.66 & 0.18 & 0.001 \\
\hline Latitude & & 0.93 & 0.01 & 0.355 \\
\hline Substrate type & & 0.91 & 0.01 & 0.365 \\
\hline Tidal level & & 2.49 & 0.09 & 0.016 \\
\hline Total regression & $F_{5,61}=7.00$ & & 0.37 & 0.0001 \\
\hline \multicolumn{5}{|c|}{ Across species values: species richness } \\
\hline Sample size & & 3.53 & 0.22 & 0.001 \\
\hline Latitude & & 0.20 & 0.00 & 0.843 \\
\hline Latitudinal range & & 3.33 & 0.21 & 0.002 \\
\hline Substrate type & & 1.24 & 0.03 & 0.223 \\
\hline Total regression & $F_{4,43}=8.96$ & & 0.46 & 0.0001 \\
\hline \multicolumn{5}{|c|}{ Across species values: prevalence } \\
\hline Sample size & & 1.30 & 0.04 & 0.200 \\
\hline Species richness & & 4.97 & 0.38 & 0.0001 \\
\hline Latitude & & 0.61 & 0.01 & 0.546 \\
\hline Latitudinal range & & 0.84 & 0.02 & 0.403 \\
\hline Substrate type & & 1.18 & 0.03 & 0.244 \\
\hline Total regression & $F_{5,41}=7.41$ & & 0.48 & 0.0001 \\
\hline
\end{tabular}

is possible if these variables are treated separately. A comparison between trematode species richness of snails from either rocky shores or soft-sediment substrates suggests that substrate type influences species richness ( 2 -tailed $t$-test, $t=4.124, \mathrm{df}=200, \mathrm{p}=0.0001$ ): snails from soft-sediments seem to harbour more trematode species than those of rocky shores (Fig. 4). However, when controlling for sample size by using residuals of the richness versus sample-size regression as corrected estimates of species richness, this difference is weakened ( $t=1.776, \mathrm{df}=200, \mathrm{p}=0.0772$ ). On the other hand, a difference was evident in trematode prevalence between rocky shores and soft-sediment shores, both before $(t=3.952, \mathrm{df}=214, \mathrm{p}=0.0001)$ and after $(t=2.762, \mathrm{df}=207, \mathrm{p}=0.0063)$ correcting for sample size: trematode infections appear more prevalent on soft-sediment substrate than on rocky shores (Fig. 4). Comparisons between tidal levels suggest that trematode species richness is higher in samples from the upper shore than in those from the lower shore (Fig. 4), either before ( $t=2.431, \mathrm{df}=79, \mathrm{p}=0.0173$ ) or 

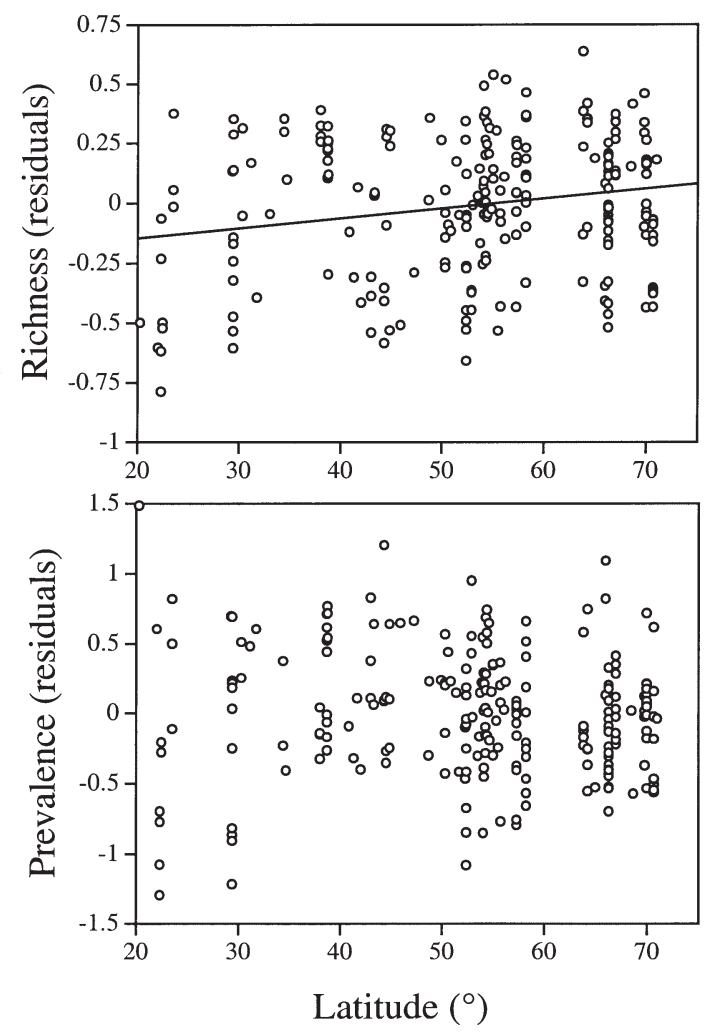

Fig. 3. Relationship between trematode species richness (top panel) and prevalence (bottom panel), and latitude at which the sample was collected, across samples (229 samples for species richness, 225 for prevalence) of snail hosts. Values for species richness are residuals from a regression of species richness against sample size, and are thus richness estimates corrected for sample size; similarly, values for prevalence are corrected for both sample size and species richness. The trend line $(y=0.004 x-0.218)$ is only shown for the significant relationship involving richness. Note: this figure includes more data points than the multiple regressions reported in the text, which included only samples for which data are also available on substrate type and tidal level.

after ( $t=2.212, \mathrm{df}=79, \mathrm{p}=0.0299$ ) correcting for sample size. There were no differences in trematode prevalence between the upper and lower shore (without correction: $t=0.367, \mathrm{df}=85, \mathrm{p}=0.715$; after correcting for sample size: $t=0.938, \mathrm{df}=78, \mathrm{p}=0.351$ ).

\section{Trematode species richness and prevalence as snail species characters}

Using only the snail species for which data were available from at least 2 samples ( 24 species for trematode species richness, 27 for prevalence), the repeatability analyses indicated that both trematode richness and prevalence can be treated as species characters (Fig. 5). Estimates of trematode species richness from

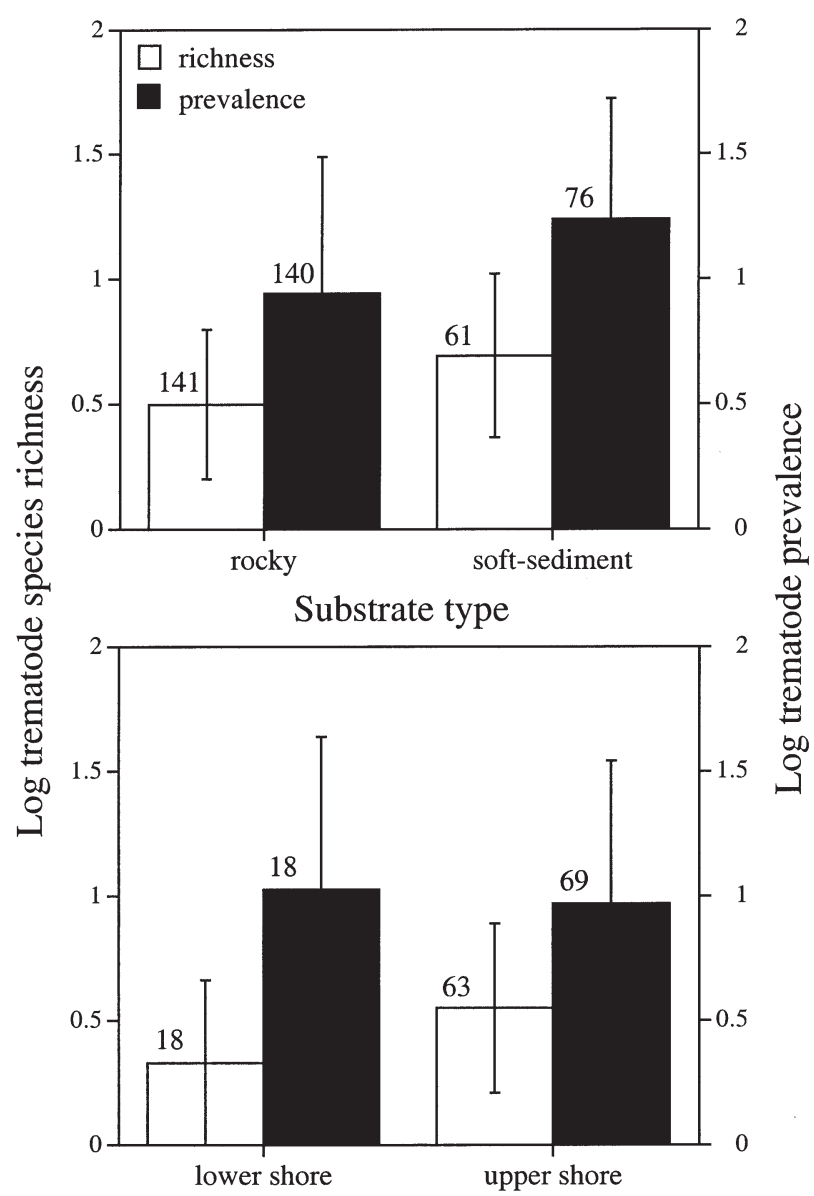

Tidal level

Fig. 4. Mean $( \pm S D)$ trematode species richness and prevalence in snail samples from either rocky or soft-sediment substrates, and from either the lower or upper shore. The numbers of samples of each type are given above the bars

different populations (or samples) of the same snail species are more similar to each other than expected by chance alone $\left(F_{23,182}=4.753, p=0.0001, r_{1}=0.32\right)$. Approximately $32 \%$ of the variation in trematode species richness among snail samples is associated with differences between snail species, rather than with differences among samples within species. Similarly, estimates of trematode prevalence from the same snail species are more similar to each other than expected by chance $\left(F_{26,196}=3.264, p=0.0001, r_{1}=0.23\right)$, with $23 \%$ of the variation among samples accounted for by differences between snail species. Thus, estimates of trematode richness and prevalence are repeatable within the same snail-host species (Fig. 5). Different estimates from the same snail species are therefore not independent from one another, i.e. not true replicates in a statistical sense, and these data should either be analysed within snail species only, or across average snail species values. 

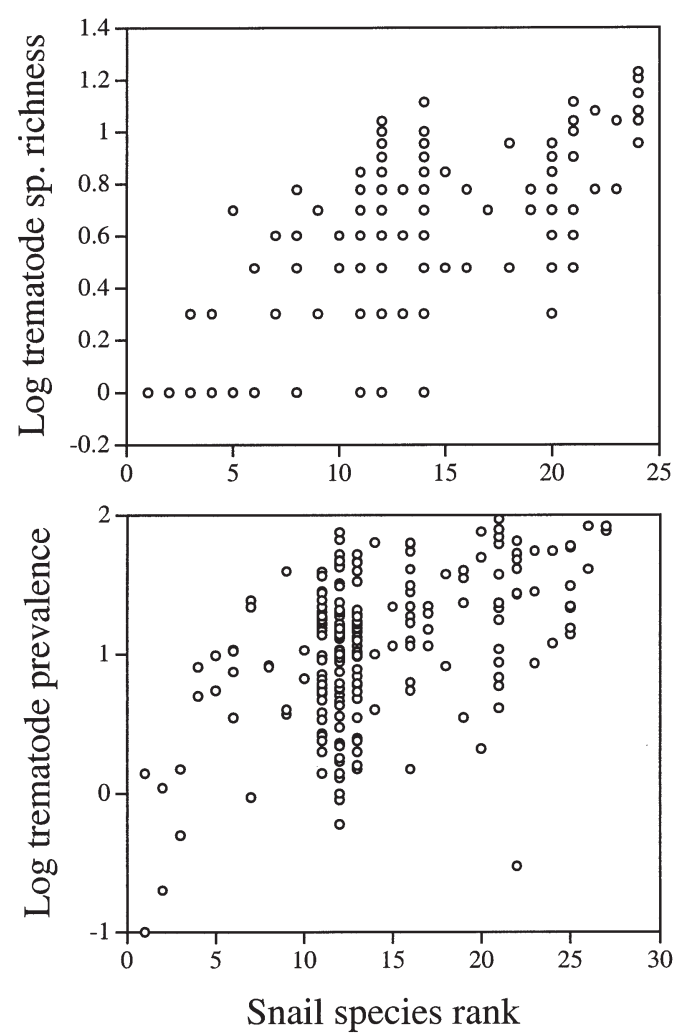

Fig. 5. Rank plots of trematode species richness and prevalence. The snail species are ranked according to their mean log-transformed values of either species richness or prevalence, with Rank 1 given to the species with the lowest mean value; all sample estimates are plotted for each species. If variation is small within compared to between snail species, we expect a relatively narrow band of points from the lower left to the upper right corner, with few or no points in either the upper left or lower right corner

\section{Analyses within species}

The only potential ecological determinant of trematode infection that varied among samples within snail species was latitude. Only 7 snail species included sufficient samples (7 or more, see Table 2) for a within-species analysis of the influence of latitude on trematode infections. After controlling for sample size, latitude correlated negatively with trematode species richness among samples in $\mathrm{Hy}$ drobia ulvae (partial regression coefficient: $r=-0.556, \mathrm{~N}$ $=11, p=0.0112)$ and positively in Littorina littorea $(r=$ $0.536, \mathrm{~N}=35, \mathrm{p}=0.0001$ ). There were no significant effects of latitude on species richness in the other snail species, and no effect of latitude on prevalence, after correction for sample size, in any of the 7 snail species.

\section{Analyses across species}

The analyses across species values are based on data from 54 snail species (Table 2). Trematode species richness correlated positively with sample size $(r=$ $0.480, N=48, p=0.0006)$, but prevalence did not ( $r=$ $0.065, N=53, p=0.646$ ). Trematode species richness and prevalence correlated positively and relatively strongly across all snail species $(r=0.651, N=47, p=$ 0.0001); the scatter of points (Fig. 6) shows a pattern that is not as 'triangular' as that across samples (see Fig. 2), but still suggests that snail species harbouring a single trematode species can show a range of prevalence, whereas those harbouring several species are invariably infected at high prevalence. The positive relationship between richness and prevalence remains strong ( $r=0.648, N=47, p=0.0001)$ after controlling species richness for the effect of sample size using a partial correlation.

The effects of latitude, latitudinal range and substrate type on trematode richness were evaluated across snail species using a multiple regression in which sample size was included as a confounding variable. The overall model explained $46 \%$ of the variance, with sample size and latitudinal range being the main predictors of trematode richness (Table 1). There was no significant effect of latitude (Fig. 7) or substrate type (Table 1). Similarly, the effect of these same predictor variables on trematode prevalence was assessed in a multiple regression that also included species richness as a possible confounding variable. The overall model explained $48 \%$ of the variation in prevalence among snail species (Table 1). We found no significant effect of latitude (Fig. 7), latitudinal range, sample size or substrate type on trematode prevalence; only species richness influenced prevalence values (Table 1 ).

Because they were each available for only few species, data on shell length, life-span and density were treated in separate correlation analyses. None of these 3 variables correlated with either trematode species richness or trematode prevalence, whether correcting for sample size or not (all $p \geq 0.15$ ).

\section{Analyses across phylogenetically independent contrasts}

A maximum of 37 independent contrasts could be derived from our working gastropod phylogeny. Among these, trematode species richness correlated positively with sample size $(r=0.525, N=37, p=$ 0.0008 ) but prevalence did not $(r=0.289, N=37, p=$ 0.083). Therefore, in subsequent analyses, species richness was always corrected for sample size using the residuals of a regression between the 2 variables forced through the origin. Species richness and prevalence were once again positively correlated $(r=0.455$, $N=37, p=0.0047$ ): of the 37 pairs of phylogenetic contrasts, 25 varied in the same direction, either both neg- 
Table 2. Mean species values for the key variables used in the analyses, for all 54 snail species. In sample size, richness and prevalence calculations, mean values are geometric means for species with $>1$ samples, i.e. they are backtransformed from log-transformed data

\begin{tabular}{|c|c|c|c|c|c|c|}
\hline $\begin{array}{l}\text { Snail } \\
\text { species }\end{array}$ & $\begin{array}{l}\text { No. } \\
\text { amples }\end{array}$ & $\begin{array}{l}\text { Sample } \\
\text { size }\end{array}$ & $\begin{array}{l}\text { Species } \\
\text { richness }\end{array}$ & $\begin{array}{c}\text { Pre- } \\
\text { valence } \\
(\%)\end{array}$ & $\begin{array}{l}\text { Lati- } \\
\text { tude } \\
\left({ }^{\circ}\right)\end{array}$ & Habitat \\
\hline Batillaria australis & 1 & 8883 & 3.0 & 23.1 & 31.8 & Soft \\
\hline Buccinum undatum & 4 & 542 & 3.2 & 16.6 & 54.5 & Soft \\
\hline Bullia digitalis & 1 & 3000 & 5.0 & - & 33.0 & Soft \\
\hline Cantharus dorbignyi & 1 & 170 & 1.0 & 1.2 & 42.0 & Soft \\
\hline Cerithidea californica & 7 & 4325 & 12.7 & 27.3 & 36.8 & Soft \\
\hline Cerithidea cingulata & 3 & 1570 & 7.6 & 20.0 & 29.4 & Soft \\
\hline Cerithidea mazatlanica & 3 & 200 & - & 13.7 & 31.0 & Soft \\
\hline Cerithidea pliculosa & 1 & 1652 & 7.0 & 52.8 & 31.2 & Soft \\
\hline Cerithidea scalariformis & 2 & 114 & 3.2 & 25.8 & 30.3 & Soft \\
\hline Cerithium moniliferum & 1 & 1500 & 11.0 & 22.0 & 23.5 & Rocky \\
\hline Clypeomorus bifasciata & 2 & 1245 & 5.2 & 17.6 & 29.4 & Soft \\
\hline Cominella glandiformis & 1 & 4254 & 3.0 & 8.1 & 43.0 & Soft \\
\hline Concholepas concholepas & as 1 & 866 & 1.0 & 9.8 & 22.0 & Rocky \\
\hline Cronia margariticola & 1 & 482 & 1.0 & 0.4 & 29.4 & Rocky \\
\hline Diloma subrostrata & 1 & 384 & 1.0 & 12.0 & 45.9 & Soft \\
\hline Epheria (Lacuna) vincta & 1 & 80 & 1.0 & 2.5 & 63.8 & Rocky \\
\hline Fissurella crassa & 1 & 136 & - & 14.0 & 20.4 & Rocky \\
\hline Fissurella cumingi & 1 & 353 & - & 64.9 & 20.4 & Rocky \\
\hline Fissurella maxima & 1 & 231 & - & 97.0 & 20.4 & Rocky \\
\hline Fissurella pulchra & 2 & 219 & - & 80.4 & 20.3 & Rocky \\
\hline Gibbula umbilicalis & 1 & 3070 & 2.0 & 2.4 & 52.4 & Rocky \\
\hline Hydrobia ulvae & 18 & 573 & 6.5 & 16.1 & 55.2 & Soft \\
\hline Hydrobia ventrosa & 4 & 4753 & 9.5 & 20.7 & 53.1 & Soft \\
\hline Ilyanassa obsoleta & 15 & 1042 & 5.5 & 21.8 & 38.6 & Soft \\
\hline Littorina fabalis & 4 & 142 & 2.9 & 7.4 & 56.2 & Rocky \\
\hline Littorina littorea & 35 & 762 & 3.3 & 9.7 & 52.8 & Rocky \\
\hline Littorina mariae & 2 & 136 & 5.0 & 7.3 & 58.3 & Rocky \\
\hline Littorina neritoides & 3 & 4477 & 4.0 & 7.9 & 51.0 & Rocky \\
\hline Littorina nigrolineata & 1 & 221 & 1.0 & 10.4 & 52.9 & Rocky \\
\hline Littorina obtusata & 35 & 334 & 3.9 & 9.1 & 63.4 & Rocky \\
\hline Littorina rudis & 3 & 110 & 1.7 & 23.8 & 53.4 & Rocky \\
\hline Littorina saxatilis & 56 & 269 & 3.3 & 9.5 & 64.8 & Rocky \\
\hline Littorina scutulata & 2 & 897 & 4.2 & 8.5 & 46.0 & Rocky \\
\hline Mitrella blanda & 1 & 282 & 1.0 & 4.3 & 29.4 & Soft \\
\hline Monilea obscura & 1 & 890 & 1.0 & 0.3 & 29.4 & Rocky \\
\hline Monodonta lineata & 1 & 455 & 1.0 & 0.2 & 52.4 & Rocky \\
\hline Morula musiva & 1 & 353 & 1.0 & 1.7 & 22.5 & Rocky \\
\hline Nassarius plicatus & 1 & 275 & 2.0 & 3.3 & 29.4 & Soft \\
\hline Neptunea arthritica & 3 & 229 & 1.0 & 8.4 & 44.3 & Soft \\
\hline Nodilittorina radiata & 2 & 686 & 1.4 & 0.5 & 22.3 & Rocky \\
\hline Nodilittorina trochoides & 2 & 1496 & 1.7 & 0.4 & 22.3 & Rocky \\
\hline Nucella lapillus & 4 & 250 & 1.4 & 18.5 & 61.6 & Rocky \\
\hline Olivella biplicata & 1 & 200 & 3.0 & 41.0 & 43.3 & Rocky \\
\hline Onoba aculeus & 3 & 121 & 3.6 & 8.2 & 64.8 & Rocky \\
\hline Patella aspera & 1 & 328 & 1.0 & 3.7 & 52.4 & Rocky \\
\hline Patella intermedia & 1 & 150 & 2.0 & 5.3 & 52.4 & Rocky \\
\hline Patella vulgata & 1 & 503 & 3.0 & 7.6 & 52.4 & Rocky \\
\hline Pirinella conica & 8 & 452 & - & 23.1 & 29.3 & Soft \\
\hline Planaxis sulcatus & 2 & 2377 & 5.5 & 58.5 & 23.5 & Rocky \\
\hline Retusa obtusa & 2 & 305 & 1.0 & 0.9 & 55.7 & Soft \\
\hline Siphonaria rosea & 1 & 516 & 2.0 & 26.6 & 29.4 & Rocky \\
\hline Thais clavigera & 1 & 429 & 1.0 & 1.4 & 22.5 & Rocky \\
\hline Turritella communis & 2 & 312 & 2.8 & 6.4 & 45.6 & Soft \\
\hline Zippora membranacea & 1 & 389 & 4.0 & 12.2 & 54.1 & Soft \\
\hline
\end{tabular}

ative or both positive (Fig. 8). Trematode species richness did not correlate with latitude $(r=-0.004, N=37, p=$ $0.98)$ and neither did prevalence $(r=$ $-0.126, \mathrm{~N}=37, \mathrm{p}=0.45$ ). Among taxa for which data were available, neither species richness $(r=-0.159, \mathrm{~N}=21, \mathrm{p}=$ $0.49)$ nor prevalence $(r=0.404, N=21$, $\mathrm{p}=0.069)$ correlated with shell size. Few phylogenetically independent contrasts could be obtained between sister taxa that differed with respect to the type of substrate on which they occurred. When values from rocky substrate taxa are consistently subtracted from those of their soft-sediment relatives, we would expect mean contrast values that differ from zero if there are differences between substrate type; no such differences were found for either trematode species richness (1-sample $t$-test: $t=1.315, \mathrm{df}=7, \mathrm{p}=0.229)$ or prevalence $(t=0.321, \mathrm{df}=7, \mathrm{p}=0.758)$.

\section{DISCUSSION}

Large-scale patterns are emerging from the many macroecological studies performed in recent years (e.g. Brown 1995, Gaston \& Blackburn 2000). The similarity among patterns found in different taxonomic assemblages offers some promise that these patterns are produced by the same general underlying processes. Our analyses searched for large-scale patterns in the richness and prevalence of trematode infections among snail populations, similar to those observed in host-parasite associations involving vertebrate hosts (Poulin 1997, M orand 2000). However, we found instead evidence suggesting that local factors (on a scale of 10 s to 100s of $\mathrm{m}$ ) play bigger roles in determining how many trematode species are present or how many snails are infected.

We carried out analyses at different levels of statistical independence. The repeatability analyses indicated that trematode species richness and prevalence could be considered as traits of snail species, and justified the use of phylogenetically independent con- 


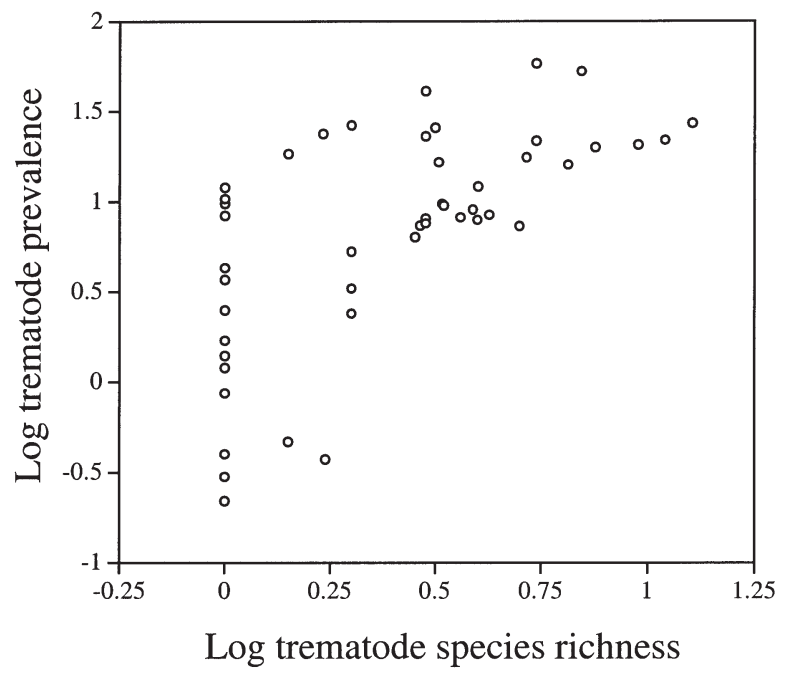

Fig. 6. Relationship between trematode prevalence and species richness across 47 species of snail hosts

trasts. There was still much variation within species in both trematode richness and prevalence, with certain samples having values several times greater than others. This observation, coupled with the lack of clear, consistent effect of the potential determinants of trematode infection examined here, suggests that local factors play a major role in determining how many trematode species infect a snail population, and at what prevalence. Phylogenetic effects may constrain the range of possible values, as shown in the repeatability analysis (see Fig. 5), but not to the extent of making these values predictable based on general features of the host or of its habitat. Since the main source of trematode-infective stages are shorebirds, our results suggest that their local abundance and diversity do not covary tightly with, for example, the latitude of a location. This is in accordance with the migratory behaviour of many shorebird species (the definitive hosts of most snail trematodes), which spans many degrees of latitude.

Two confounding variables had an effect on trematode species richness. Sample size was always expected to influence estimates of species richness (Walther et al. 1995). Our data set excluded samples of fewer than 75 snails; most samples included a few to several hundred snails. If an effect of sample size is still detectable among relatively large samples, it suggests that trematodes are difficult to find, because of generally low prevalence or spatially patchy distributions, and that data from small samples must be interpreted with caution. The other confounding variable that influenced trematode species richness was latitudinal range. Species of snails sampled from a range of different latitudes displayed higher mean richness values than species sampled from a single latitude. Clearly,
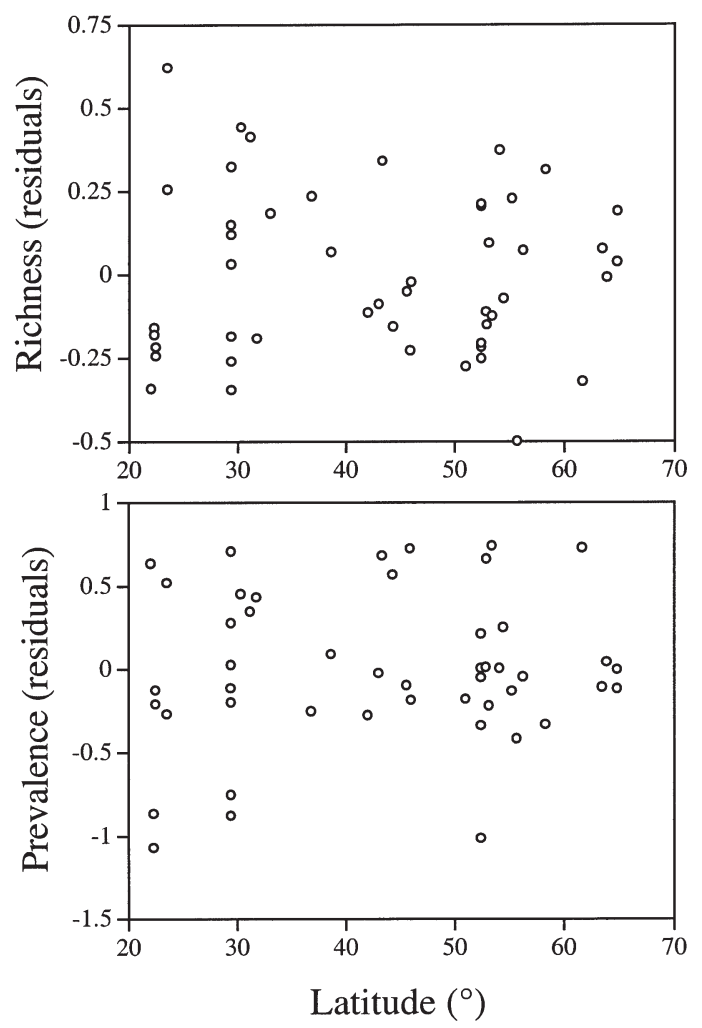

Fig. 7. Relationship between trematode species richness (top panel) and prevalence (bottom panel), and mean latitude at which the species was collected, across snail species (48 for species richness, 47 for prevalence). Values for species richness are residuals from a regression of species richness against sample size and latitudinal range, and are thus richness estimates corrected for both these variables; similarly, values for prevalence are corrected for species richness

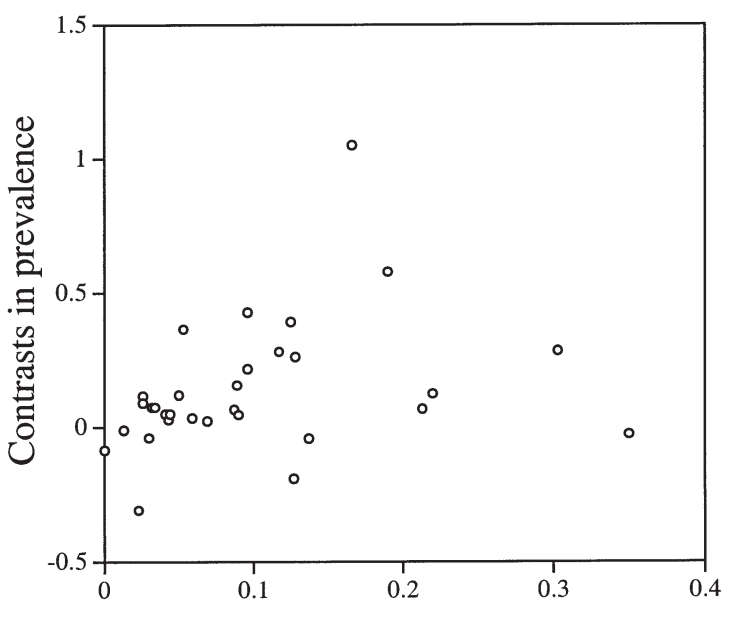

Contrasts in species richness

Fig. 8. Relationship between trematode prevalence and species richness across 37 phylogenetically independent contrasts derived from the phylogeny of snail-host species. Contrasts in species richness are corrected for sample size 
for a given snail species, the more localities sampled, the more likely it is that a site with high species richness will be included, inflating the mean richness score of that species. Since shorebirds are not evenly distributed along the coastline, but often show strong preferences for certain feeding or roosting sites (e.g. M ouritsen 1994), this pattern is understandable. On its own, this effect highlights the importance of local factors in determining species richness.

The only association that emerged from analyses at all levels was the positive relationship between trematode species richness and prevalence. This relationship can be explained by the strong interspecific antagonism common between different trematode species in the same snail, as discussed in detail by Sousa (1993) and Kuris \& Lafferty (1994). Many species of trematodes are capable of excluding other species from their snail host, such that multiple infections of the same snail individual are very rare, much less frequent than expected on the basis of the respective prevalence of different co-occurring trematode species. Thus, the prevalences of different species add up to one another in a snail population: if 2 trematode species occur with prevalences of 5 and $10 \%$ respectively, we can usually expect close to $15 \%$ of snails to be infected. Our results confirm the additive nature of trematode prevalences at the host population level. From the host's perspective, this means that each new trematode species colonising their locality will impose an additional cost, and exert an additional selective pressure.

The effect of latitude observed across samples disappeared at higher levels of independence. Only within 2 snail species is there some suggestion of latitudinal gradients in trematode species richness. These results require closer scrutiny, however. In Littorina littorea, the apparent positive relationship between trematode species richness and latitude is due to the inclusion in the analysis of a few samples from North America. The invasion of North America by European L. littorea is a relatively recent event, and we might expect that North A merican snail populations would have a lower richness of trematode species, having lost European ones and having had too little time to be colonised by new species. The relationship between trematode richness and latitude disappears if we include only European samples of $L$. littorea. In the case of Hydrobia ulvae samples, a negative relationship was found between latitude and trematode richness. Here again, the relationship may be an artefact caused by a particularly high species richness in snails from the southern North Sea region. Since the intertidal flats of this region serve as the main, common feeding/stop-over area for both Nearctic and Palaearctic shorebirds migrating along the east Atlantic flyway (Smit \& Piersma 1989), a high trematode species richness is expected there, and represents an effect of the region rather than latitude.

The overall impression one gets from these results is that there are no latitudinal gradients in species richness among snail-trematode systems. Although latitudinal diversity gradients are common (Rosenzweig 1995, Gaston \& Blackburn 2000), including among ectoparasites of fish (Rohde 1993, 1999, Poulin \& Rohde 1997, Rohde \& Heap 1998), they are not universal. Several detailed comparative studies have failed to find latitudinal effects, or have observed a counterintuitive increase in richness at temperate latitudes, among internal helminth parasites of vertebrates, including adult trematodes in fish and birds, whose larvae occur in intertidal gastropods (Poulin 1995, 2001, Rohde \& Heap 1998, Choudhury \& Dick 2000). Thus the absence of a latitudinal gradient in trematode species richness in snails is not necessarily a surprise. Before concluding that latitude has no effect on trematode richness in snails, however, 2 cautionary remarks are necessary. First, the great majority of our data points came from the northern hemisphere. This may not be important, but it illustrates the imbalance in the available information. Second, we had no data from latitudes below $20^{\circ}$ north or south; all our data came from latitudes between approximately 20 and $70^{\circ}$. In other latitudinal gradients reported in the literature, exclusion of data from latitudes lower than $20^{\circ}$ would not mask existing trends (e.g. Attrill et al. 2001). Still, it is possible that tropical snails exhibit high trematode species richness that would have influenced the analyses; the effect of latitude will need to be revisited when data from low latitudes have been collected and published.

Substrate type and tidal levels appeared to be potential determinants of trematode infections across all samples. The effect of substrate disappeared at other levels of analysis, and that of tidal levels could not be assessed further. The apparent effect of tidal level may be confounded by the fact that some trematodes alter the vertical zonation of their snail hosts (Curtis 1987, McCarthy et al. 2000). Nevertheless, these 2 local habitat features may still be important, because they are good predictors of the small-scale distribution of shorebird abundance and diversity that do differ between hard and soft-bottom habitats and different shore heights (e.g. Nybakken 1993, Mouritsen 1994).

Overall, our analyses indicate that the importance of small-scale, local factors overrides that of larger-scale factors, rendering difficult the detection of large-scale patterns in species richness or prevalence of trematode infections in snails. Small-scale processes also appear more important than large-scale ones in determining the abundance or diversity of intertidal organisms, including snails (e.g. Underwood \& Chapman 1998, 
Blanchard \& Bourget 1999, Benedetti-Cecchi 2001). It must be emphasised, however, that our analyses all focused on trematode species richness per snail species, and not on absolute species richness or richness per unit area. Studies at those levels will be more difficult, but could reveal the sort of patterns that we searched for at the host level.

Acknowledgements. This work was partially supported by a research grant from the Marsden Fund (New Zealand) and the Danish Natural Science Research Council.

\section{LITERATURE CITED}

Arneberg P, Skorping A, Read AF (1997) Is population density a species character? Comparative analyses of the nematode parasites of mammals. Oikos 80:289-300

Attrill MJ , Stafford R, Rowden AA (2001) Latitudinal diversity patterns in estuarine tidal flats: indications of a global cline. Ecography 24:318-324

Beesley PL, Ross GJ B, Wells A (1998) Mollusca: the southern synthesis. Fauna of Australia, Vol 5. CSIRO Publishing, Melbourne

Benedetti-Cecchi L (2001) Variability in abundance of algae and invertebrates at different spatial scales on rocky sea shores. Mar Ecol Prog Ser 215:79-92

Blanchard D, Bourget E (1999) Scales of coastal heterogeneity: influence on intertidal community structure. $\mathrm{M}$ ar Ecol Prog Ser 179:163-173

Brown J H (1995) Macroecology. University of Chicago Press, Chicago

Choudhury A, Dick TA (2000) Richness and diversity of helminth communities in tropical freshwater fishes: empirical evidence. J Biogeogr 27:935-956

Curtis LA (1987) Vertical distribution of an estuarine snail altered by a parasite. Science 235:1509-1511

Curtis LA (1997) Ilyanassa obsoleta (Gastropoda) as a host for trematodes in Delaware estuaries. J Parasitol 83:793-803

Felsenstein J (1985) Phylogenies and the comparative method. Am Nat 125:1-15

Garland T J r, Harvey PH, Ives AR (1992) Procedures for the analysis of comparative data using phylogenetically independent contrasts. Syst Biol 41:18-32

Gaston KJ, Blackburn TM (2000) Pattern and process in macroecology. Blackwell Science, Oxford

Gregory RD, Blackburn TM (1991) Parasite prevalence and host sample size. Parasitol Today 7:316-318

Harvey PH (1996) Phylogenies for ecologists. J A nim Ecol 65: 255-263

Harvey PH, Pagel M D (1991) The comparative method in evolutionary biology. Oxford University Press, Oxford

Hickman CS (1996) Phylogeny and patterns of evolutionary radiation in trochoidean gastropods. In: Taylor J (ed) Origin and evolutionary radiation of the mollusca. Oxford University Press, Oxford, p 177-198

Houbrick RS (1984) Revision of higher taxa in genus Cerithidea (M esogastropoda: Potamididae) based on comparative morphology and biological data. Am Malacol Bull 2: $1-20$

Hudson PJ, Rizzoli A, Grenfell BT, Heesterbeek H, Dobson AP (2002) The ecology of wildlife diseases. Oxford University Press, Oxford

Huxham D, Raffaelli D, Pike A (1993) The influence of Cryp- tocotyle lingua (Digenea: Platyhelminthes) infections on the survival and fecundity of Littorina littorea (Gastropoda: Prosobranchia): an ecological approach. J Exp Mar Biol Ecol 168:223-238

J ensen KT, Mouritsen KN (1992) Mass mortality in two common soft-bottom invertebrates, Hydrobia ulvae and Corophium volutator - the possible role of trematodes. Helgol Meeresunters 46:329-339

Kantor YI (1996) Phylogeny and relationships of Neogastropoda. In: Taylor J (ed) Origin and evolutionary radiation of the mollusca. Oxford University Press, Oxford, p 221-230

Kearn GC (1998) Parasitism and the Platyhelminths. Chapman \& Hall, London

Krist AC (2001) Variation in fecundity among populations of snails is predicted by prevalence of castrating parasites. Evol Ecol Res 3:191-197

Kuris AM, Lafferty KD (1994) Community structure: larval trematodes in snail hosts. Annu Rev Ecol Syst 25: 189-217

Lafferty KD (1993a) Effect of parasitic castration on growth, reproduction and population dynamics of the marine snail Cerithidea californica. M ar Ecol Prog Ser 96:229-237

Lafferty KD (1993b) The marine snail, Cerithidea californica, matures at smaller sizes where parasitism is high. Oikos 68:3-11

Lauckner G (1987) Ecological effects of larval trematode infestations on littoral marine invertebrate populations. Int J Parasitol 17:391-398

Lawton J H (1999) Are there general laws in ecology? Oikos 84:177-192

McCarthy HO, Fitzpatrick S, Irwin SWB (2000) A transmissible trematode affects the direction and rhythm of movement in a marine gastropod. Anim Behav 59:1161-1166

M orand S (2000) Wormy world: comparative tests of theoretical hypotheses on parasite species richness. In: Poulin $\mathrm{R}_{\text {, }}$ M orand S, Skorping A (eds) Evolutionary biology of hostparasite relationships: theory meets reality. Elsevier Science, A msterdam, p 63-79

Morand S, Poulin R (1998) Density, body mass and parasite species richness of terrestrial mammals. Evol Ecol 12: 717-727

Mouritsen KN (1994) Day and night feeding in dunlins Calidris alpina: choice of habitat, foraging technique and prey. J Avian Biol 25: 55-62

Mouritsen KN, Poulin R (2002) Parasitism, community structure and biodiversity in intertidal ecosystems. Parasitology (Suppl) 124:S101-S117

Nybakken J W (1993) M arine biology: an ecological approach, 3rd edn. Harper Collins, New York

Pearson EJ , Cheng TC (1985) Studies of parasitic castration: occurrence of a gametogenesis-inhibiting factor in extract of Zoogonus lasius (Trematoda). J Invertebr Pathol 46: 239-246

Pechenik J A, Fried B, Simpkins HL (2001) Crepidula fornicata is not a first intermediate host for trematodes: who is? J Exp Mar Biol Ecol 261:211-224

Pohley WJ (1976) Relationships among three species of Littorina and their larval Digenea. Mar Biol 37:179-186

Ponder WF, Lindberg DR (1997) Towards a phylogeny of gastropod molluscs: an analysis using morphological characters. Zool J Linn Soc 119:83-265

Poulin R (1995) Phylogeny, ecology, and the richness of parasite communities in vertebrates. Ecol Monogr 65: 283-302

Poulin R (1997) Species richness of parasite assemblages: evolution and patterns. Annu Rev Ecol Syst 28:341-358 
Poulin R (2001) Another look at the richness of helminth communities in tropical freshwater fish. J Biogeogr 28: 737-743

Poulin R, Rohde K (1997) Comparing the richness of metazoan ectoparasite communities of marine fishes: controlling for host phylogeny. Oecologia 110:278-283

Poulin R, M orand S, Skorping A (2000) Evolutionary biology of host-parasite relationships: theory meets reality. Elsevier Science, A msterdam

Purvis A, Rambaut A (1994) Comparative Analysis by Independent Contrasts (C.A.I.C.), version 2.0. Oxford University, Oxford

Reid DG (1990) A cladistic phylogeny of the genus Littorina (Gastropoda): implications for evolution of reproductive strategies and for classification. Hydrobiologia 193: 1-19

Reid DG, Rumbak E, Thomas RH (1996) DNA, morphology and fossils: phylogeny and evolutionary rates of the gastropod genus Littorina. Phil Trans R Soc Lond B 351:877-895

Ricciardi A, Bourget E (1999) Global patterns of macroinvertebrate biomass in marine intertidal communities. $\mathrm{M}$ ar Ecol Prog Ser 185:21-35

Rohde K (1993) Ecology of marine parasites, 2nd edn. CAB International, Wallingford

Rohde K (1999) Latitudinal gradients in species diversity and Rapoport's rule revisited: a review of recent work and what can parasites teach us about the causes of the gradients? Ecography 22:593-613

Rohde K, Heap M (1998) Latitudinal differences in species and community richness and in community structure of metazoan endo- and ectoparasites of marine teleost fish. Int J Parasitol 28:461-474

Editorial responsibility: Otto Kinne (Editor),

Oldendorf/Luhe, Germany
Rosenzweig ML (1995) Species diversity in space and time. Cambridge University Press, Cambridge

Ruiz GM (1991) Consequences of parasitism to marine invertebrates: host evolution? Am Zool 31:831-839

Smit CJ , Piersma T (1989) Numbers, midwinter distribution, and migration of wader populations using the east Atlantic flyway. IWRB Spec Publ Can Wildl Serv 9:24-63

Smith NF (2001) Spatial heterogeneity in recruitment of larval trematodes to snail intermediate hosts. Oecologia 127: 115- 122

Sokal RR, Rohlf FJ (1995) Biometry, 3rd edn. WH Freeman, New York

Sousa WP (1983) Host life history and the effect of parasitic castration on growth: a field study of Cerithidea californica Haldemann (Gastropoda: Prosobranchia) and its trematode parasites. J Exp M ar Biol Ecol 73:273-296

Sousa WP (1993) Interspecific antagonism and species coexistence in a diverse guild of larval trematode parasites. Ecol M onogr 63:103-128

Underwood AJ , Chapman MG (1998) A method for analysing spatial scales of variation in composition of assemblages. Oecologia 117:570-578

Walther BA, Cotgreave P, Price RD, Gregory RD, Clayton DH (1995) Sampling effort and parasite species richness. Parasitol Today 11:306-310

Westoby M, Leishman MR, Lord J M (1995a) On misinterpreting the 'phylogenetic correction'. J Ecol 83:531-534

Westoby M, Leishman M R, Lord J M (1995b) Further remarks on phylogenetic correction. J Ecol 83:727-734

Winnepenninckx B, Steiner G, Backeljau T, De Wachter R (1998) Details of gastropod phylogeny inferred from $18 S$ rRNA sequences. Mol Phyl Evol 9:55-63

Submitted: September 18, 2002; Accepted: February 11, 2003

Proofs received from author(s): May 2, 2003 